\title{
The Cardiac Ganglia in Streptozotocin-Induced Diabetic Rats*
}

\author{
A. A. J. Kamal, S. S. W. Tay and W. C. Wong \\ Department of Anatomy, Faculty of Medicine, National University of Singapore, Singapore
}

Received June 4, 1990

Summary. The ultrastructure of the cardiac ganglia of streptozotocin-induced diabetic rats was studied at survival times of 3 and 7 days, 1, 3, 6, 9 and 12 months. At 3-7 days post-induction, some intracardiac neurons showed an overall increase in electron density, with the dendrites darkening first. Some of the affected dendrites appeared jet black and their intracytoplasmic organelles were hardly distinguishable except for some swollen mitochondria. Both electron dense and lucent types of degenerating axon terminals were observed in the interstitial spaces. Several myelinated and unmyelinated axons also showed early signs of degeneration.

At 1-6 months post-induction, numerous myelinated and unmyelinated axons were shown to be degenerated. The majority of the intracardiac neurons appeared to be normal. Numerous macrophages containing phagosomes were found in the interstitial spaces. At 9-12 months post-induction, macrophages containing engulfed debris were still commonly observed amongst the neuronal profiles, which appeared to be morphologically normal.

It is concluded that degenerative changes occur in the cardiac ganglia of streptozotocin-induced diabetic rats and that these changes appear to be both progressive and prolonged.

The ultrastructure of the normal mammalian cardiac ganglia has been reported by many workers (VIRAGH and PorTe, 1961; YAMAUCHI, 1969; MALOR et al., 1974; ZYPEN et al., 1974; PAPKA, 1976; ELLISON and HiBBS, 1976; PARDINI et al., 1987). Recently, the effects of unilateral and bilateral vagotomy on the ultrastructure of the cardiac ganglia of the monkey have been described (TAY, WONG and LING, 1984; WONG et al., 1987). The ultrastructure of cardiac ganglia of the newborn guinea pig has been studied in vitro (KoBayashi, Hassall and BuRnstock, 1986).
So far, the ultrastructure of the cardiac ganglia in chemically-induced diabetic mammals does not seem to have been examined. Only TsujimurA et al. (1986) found morphological changes in the autonomic ganglion cells of the heart of diabetic patients at the light microscopic level. The purpose of the present study was to determine, at the ultrastructural level, the changes in the cardiac ganglia of streptozotocininduced diabetic rats. A preliminary report of the findings has been published (KAMAL, TAY and WONG, 1988).

\section{MATERIALS AND METHODS}

A total of 56 male Wistar rats weighing $200-250 \mathrm{~g}$ were used for this study. The rats were grouped into seven batches, each batch comprising four streptozotocin-induced rats and four saline-injected control rats. Diabetes in the rats was induced using a freshly prepared solution of streptozotocin $(60 \mathrm{mg} / \mathrm{kg}$ body weight) in $0.01 \mathrm{M}$ citrate buffer $(\mathrm{pH} 4.5)$ at a concentration of $30 \mathrm{mg} / \mathrm{ml}$ buffer solution.

Diabetic-induction was performed under aseptic conditions. Each rat was given a single intravenous injection of streptozotocin or saline via the right external jugular vein using a $1 \mathrm{ml}$ syringe (Terumo $27 \mathrm{G})$. The animals were allowed to survive for periods of 3 and 7 days, 1, 3, 6, 9 and 12 months before they were killed by perfusion.

Blood glucose samples were measured with a blood glucometer (Ames Glucometer II). Under light ether anaesthesia, the tip of the tail was cut, and a drop of blood placed on a blood glucose stick (Ames Glucostix). The glucose stick was placed in the glucometer, and the blood glucose level was then read from the

*This work was supported by research grant RP870304 from the National University of Singapore. 


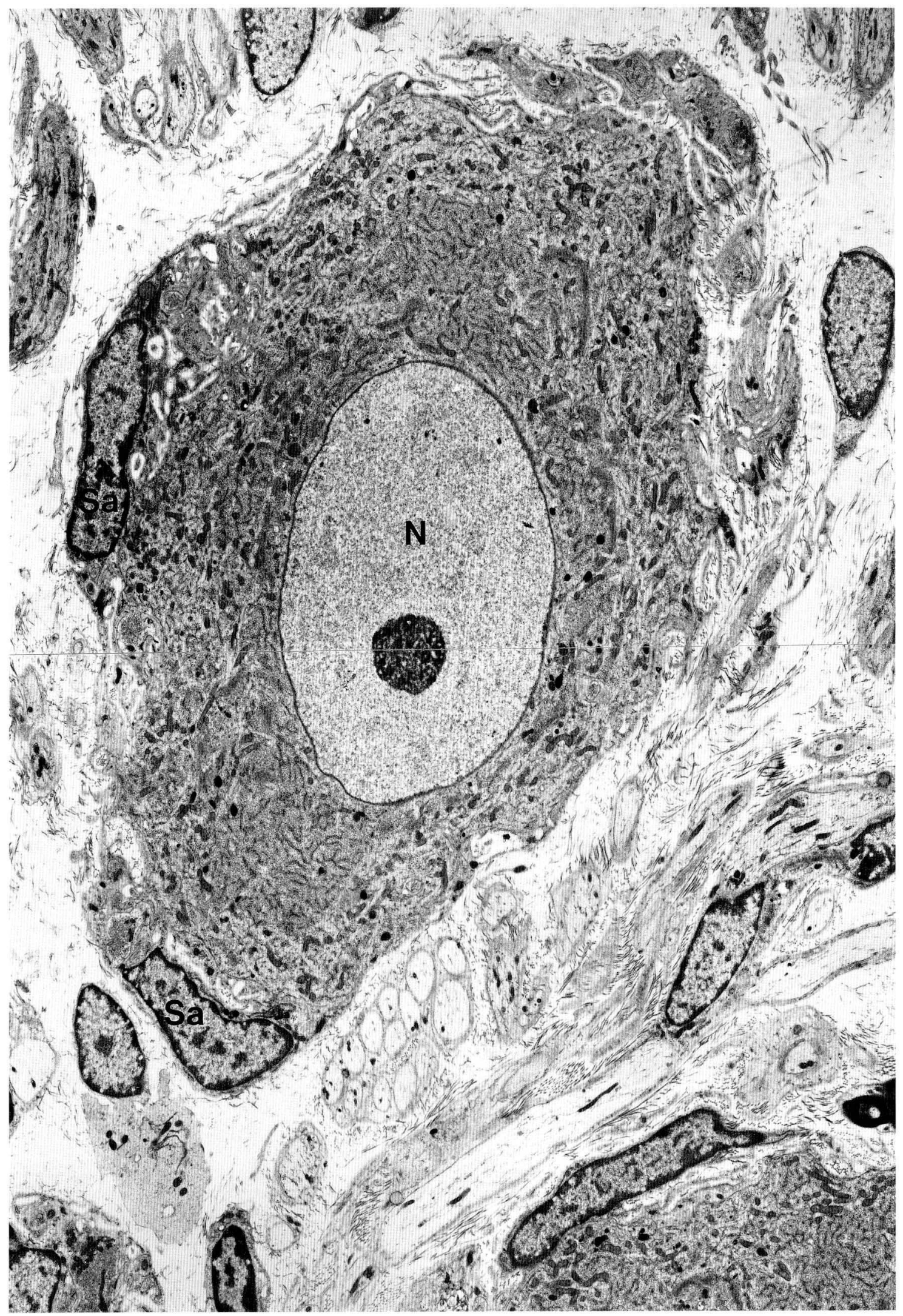

Fig. 1. An electron micrograph montage of a normal cardiac neuron. Note the pale nucleus $(N)$ containing a prominent nucleolus, Golgi apparatus, numerous mitochondria and rough endoplasmic reticulum. $\mathrm{Sa}$ satellite cell. Saline-injected control rat. $\times 4,700$ 


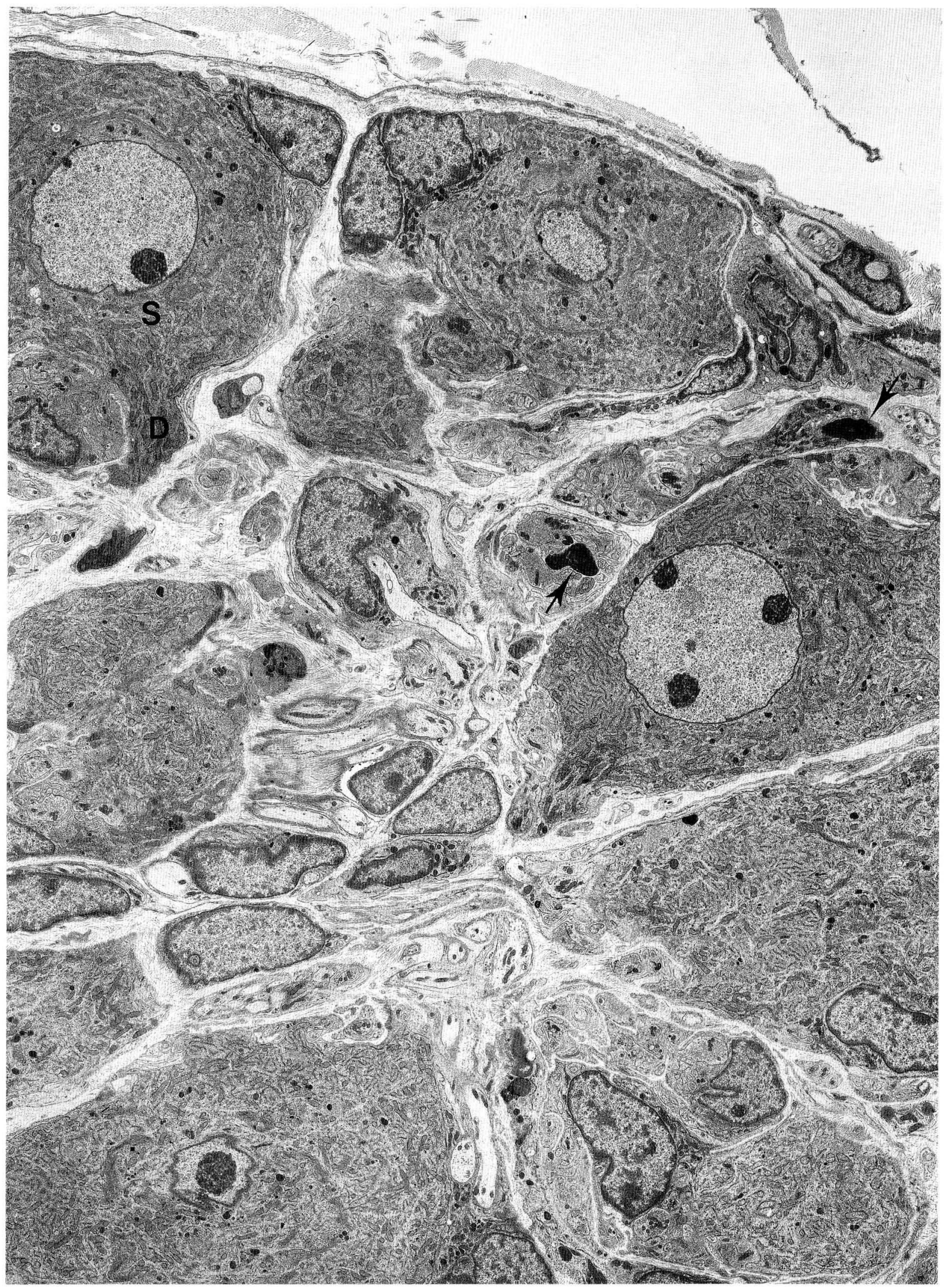

Fig. 2. Electron micrograph montage showing an affected neuron with a degenerating dendrite $(D)$ emerging from its soma $(S)$. Two detached jet black dendrites (arrows) appear to be derived from the adjacent neurons. 3 days post-induction. $\times 3,000$ 
digital display. Blood glucose levels for each rat were measured before diabetic induction, $24 \mathrm{~h}$ after induction, and immediately before sacrifice. Rats were considered diabetic when blood glucose concentrations exceeded $400 \mathrm{mg} / \mathrm{dl}$ just before sacrifice. After the relevant post-diabetes survival period, each rat was anaesthetized with sodium pentobarbital $(60$ $\mathrm{mg} / \mathrm{kg}$ ) and perfused. Before perfusion, tracheostomy was carried out and artificial respiration maintained with a Palmer animal ventilator (Model No. 5235). Five minutes before perfusion, 1000 units of heparin and $1 \mathrm{ml}$ of $1 \%$ sodium nitrite per $\mathrm{kg}$ body weight were given by intracardiac injection. The animal was perfused through the left ventricle with $100 \mathrm{ml}$ of Ringer's solution ( $\mathrm{pH}$ 7.4) followed by $300 \mathrm{ml}$ of mixed aldehyde solution ( $2 \%$ paraformaldehyde plus $3 \%$ glutaraldehyde) in $0.1 \mathrm{M}$ cacodylate buffer.

Tissue blocks measuring $0.5 \mathrm{~mm}$ in thickness were taken from the posterior wall of the heart and postfixed in the aldehyde solution overnight. After rinsing in ice-cold, $0.1 \mathrm{M}$ cacodylate buffer (pH 7.4) containing $5 \%$ sucrose, the tissue blocks were post-fixed in $1 \%$ osmium tetroxide containing $1.5 \%$ potassium ferrocyanide for $2 \mathrm{~h}$. The tissue blocks were then dehydrated in an ascending series of ethanol and embedded in Araldite.

Semithin $1 \mu \mathrm{m}$ thick sections were cut with a Reichert OMU4 ultramicrotome and stained with 1\% methylene blue and azure II. Selected areas of the blocks containing cardiac ganglia were trimmed for ultrathin sectioning. The ultrathin sections were mounted on coated grids, doubly stained with uranyl acetate and lead citrate and viewed in a Hitachi HS8 electron microscope.

\section{RESULTS}

\section{Control animals}

The ultrastructure of the cardiac neurons in the control saline-injected animals resembled that described in other mammals. The cells measured 8-50 $\mu \mathrm{m}$ in diameter, each usually possessing a centrally placed nucleus with a prominent nucleolus (Fig. 1). Interspersed in the cytoplasm were numerous mitochondria, cisterns of rough endoplasmic reticulum, glycogen particles, randomized ribosomes and occasional lipofuscin granules and lipid bodies (Fig. 1). Each cell was surrounded by one or more satellite cells. Each of these satellite cells was characterized by an elongated nucleus containing scattered chromatin materials. In the interstitial space were numerous myelinated and unmyelinated axons, Schwann cells, fibroblasts and an occasional macrophage.

\section{Experimental animals}

\section{Cardiac neurons}

As early as 3-7 days post-induction, electron dense degenerating dendrites of intrinsic neurons were observed in the cardiac ganglia. These electron dense dendrites were either still attached to the neuronal somata (Figs. 2,3) or appeared detached in the sections. The earliest sign appeared to be an accumulation of electron dense particles in the cytoplasm of the cell body, which probably accounted for its increase in electron density. At this interval, in the majority of affected neurons, the nucleus and nucleolus appeared normal, though accumulations of mitochondria were recognized in the electron dense dendrites (Figs. 2, 3). The cisterns of the rough endoplasmic reticulum were more distinct, with dispersion of ribosomes throughout the cytoplasm. There was also an overall increase in the number of neurofilaments in the darkened dendrites. Some of the affected dendrites appeared jet black, so that their intracytoplasmic organelles were hardly distinguishable except for a few pale mitochondria present (Fig. 3). There appeared to be a gradation of changes amongst the affected neurons after the onset of diabetes mellitus. Some of them showed drastically affected dendrites, while others were only slightly altered. Several detached dendritic profiles were in the process of being engulfed by the adjacent satellite cells.

Fig. 3. High magnification of a portion of a cardiac neuron showing early degeneration in the dendrite $(D)$. There is an overall increase in electron density of the dendrite due to an accumulation of electron dense particles in the cytoplasm. Another jet black dendrite (arrow) lies close to the neuronal soma (S). 3 days post-induction. $\times$ 7,900

Fig. 4. A degenerating electron lucent axon terminal $(A)$ showing a swollen mitochondrion and the clustering of small agranular synaptic vesicles. Note its close proximity to the cell soma $(S)$. 7 days post-induction. $\times 23,000$

Fig. 5. High magnification of a degenerating axon terminal. Numerous electron dense glycogen particles are clustered around a vacuole $(V)$. Note the numerous small agranular synaptic vesicles and swollen mitochondria. 1 month post-induction. $\times 17,000$ 


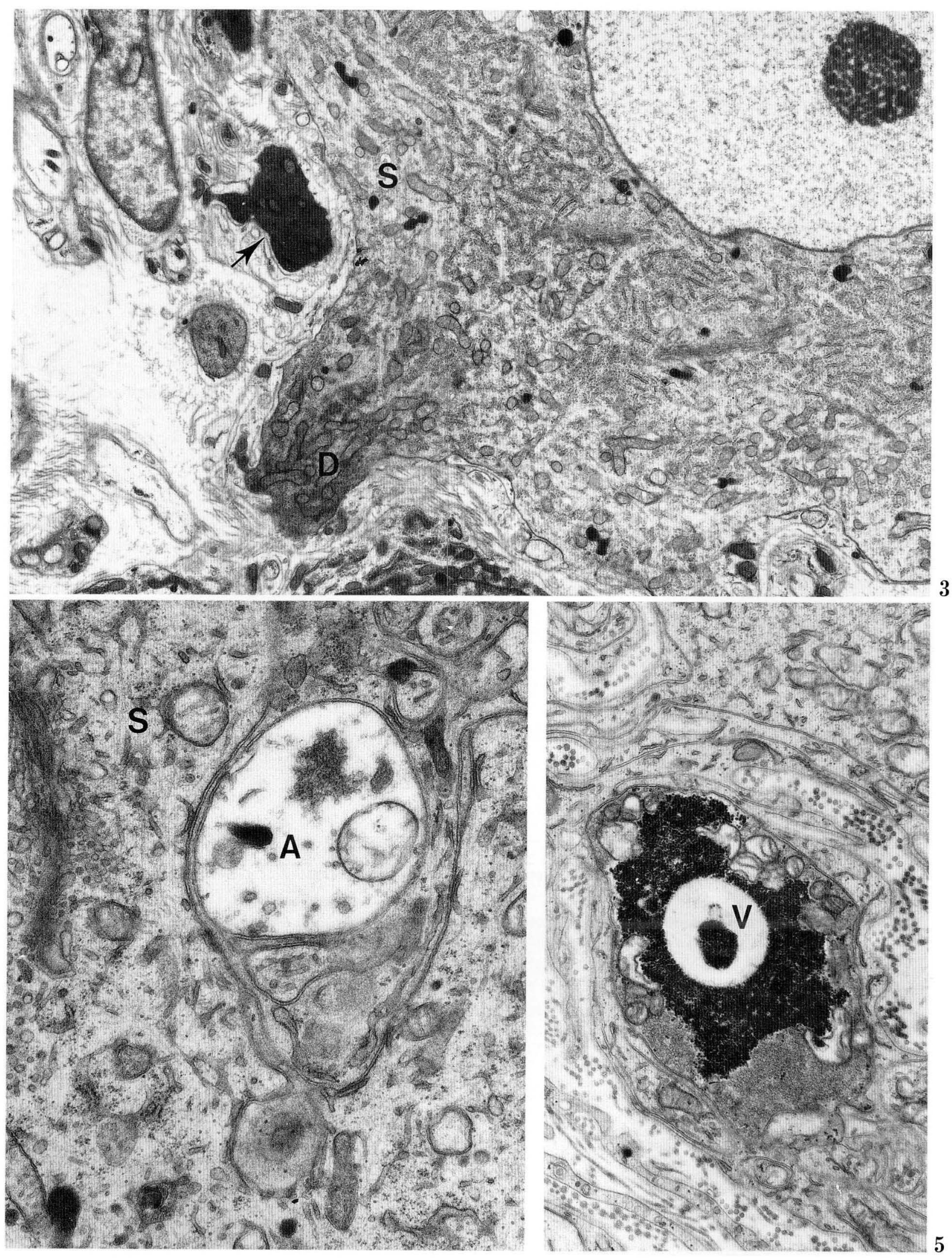

Figs. 3-5. Legends on the opposite page. 

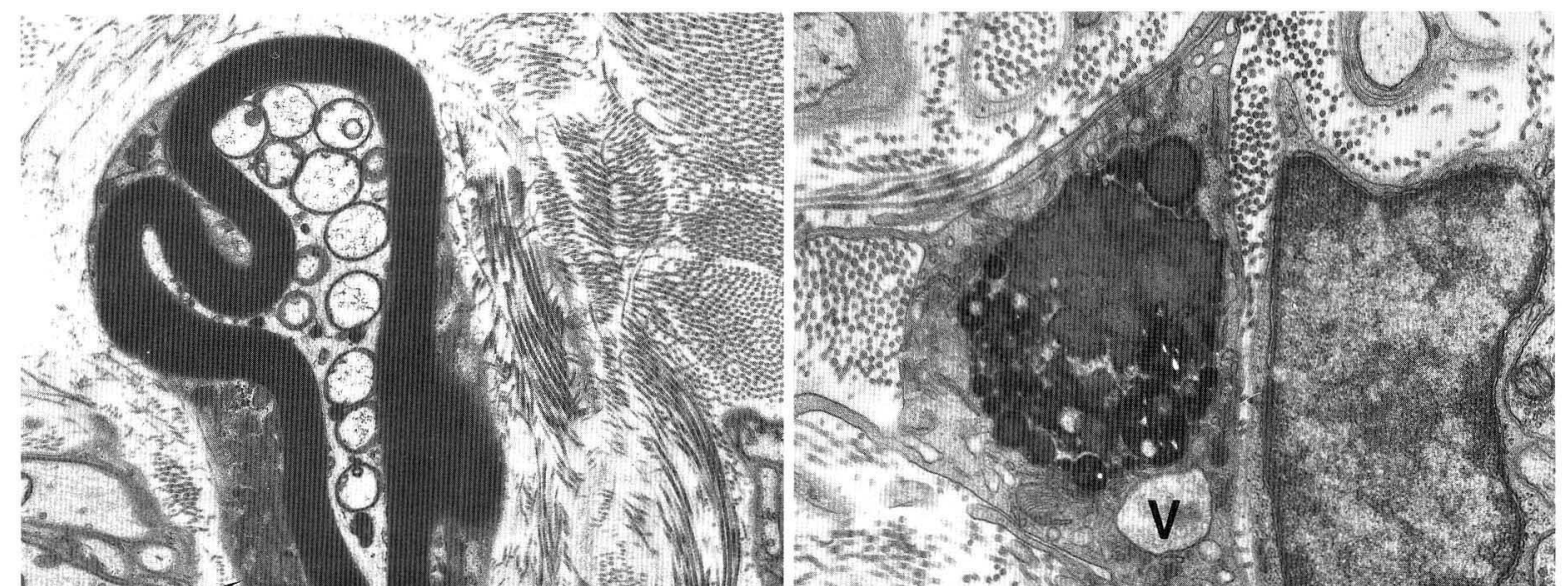

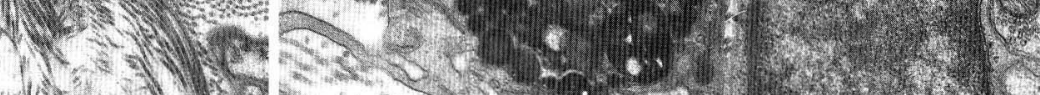

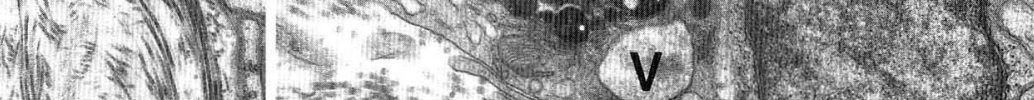
(1)

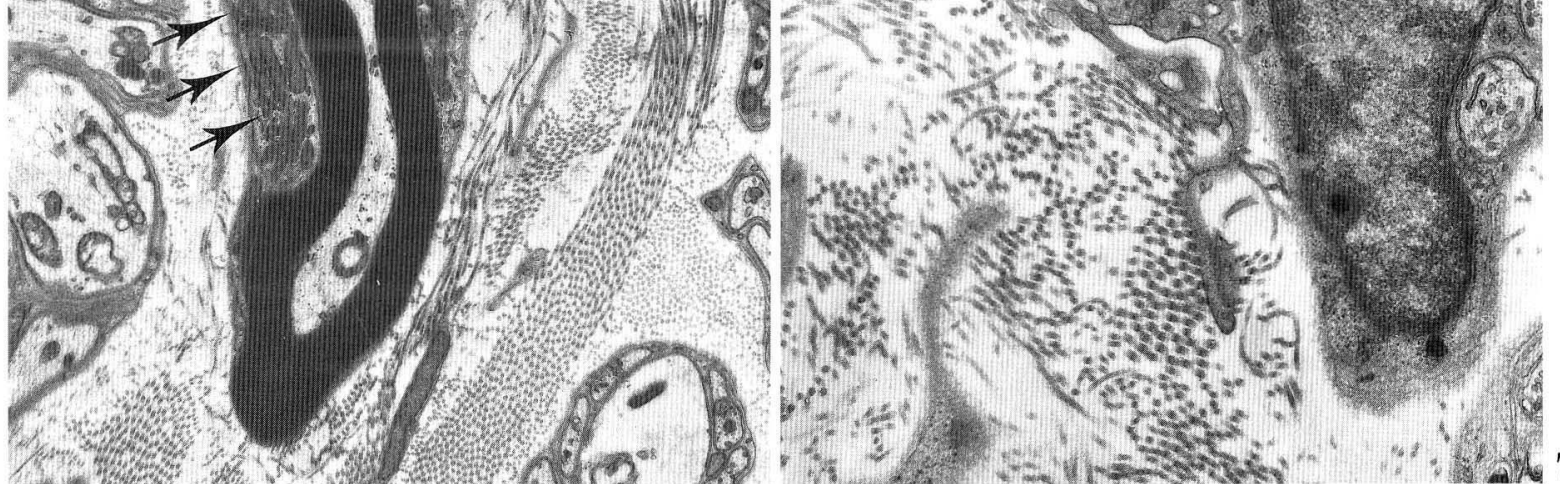

6
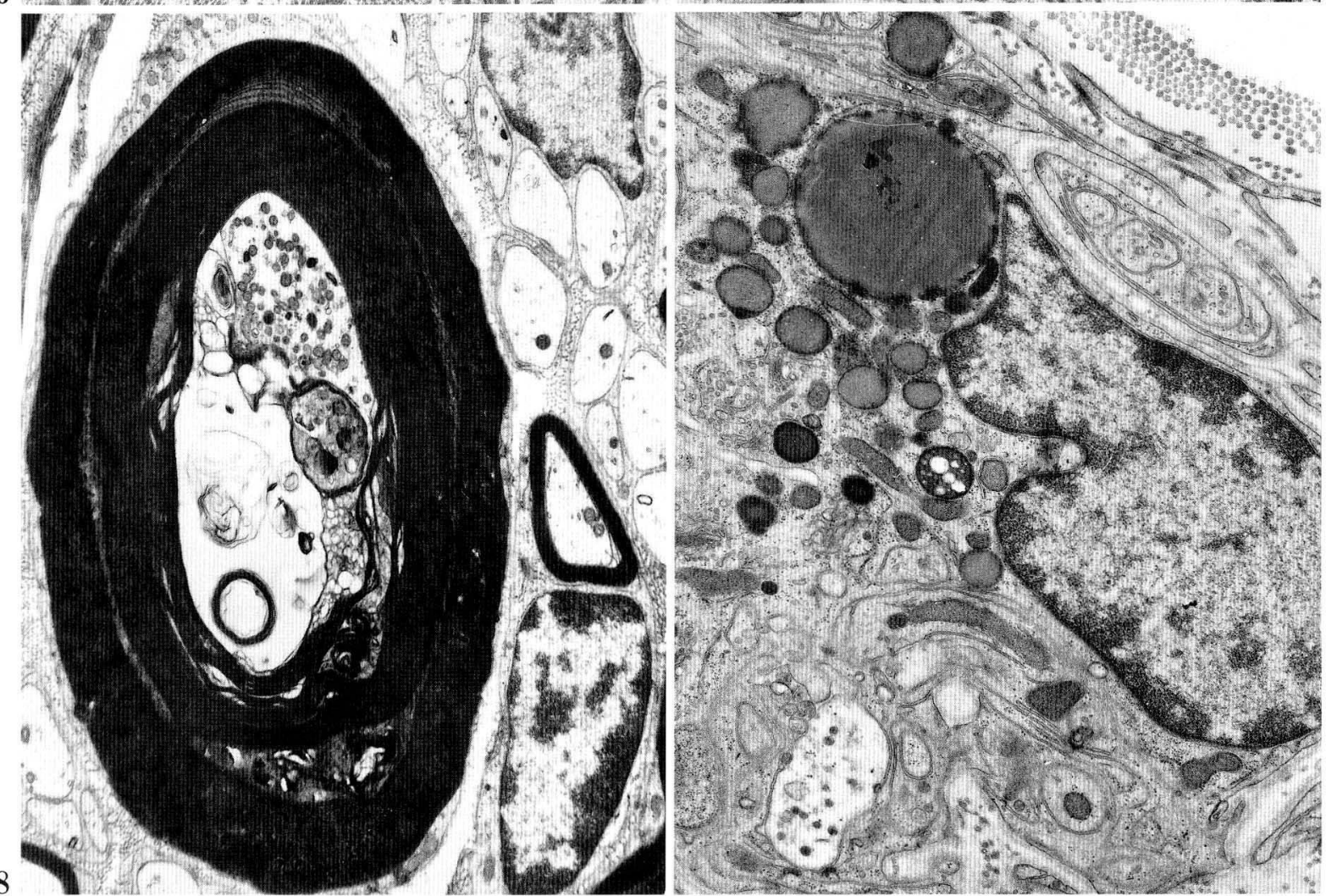

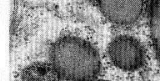

(1) n

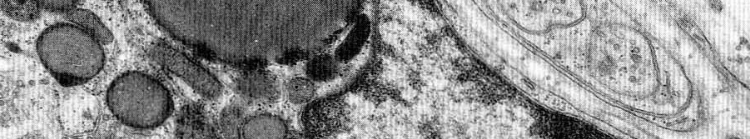

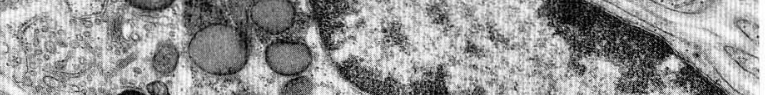

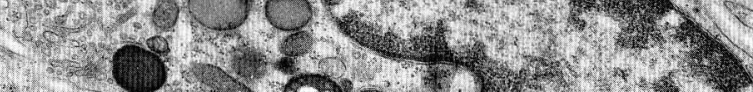

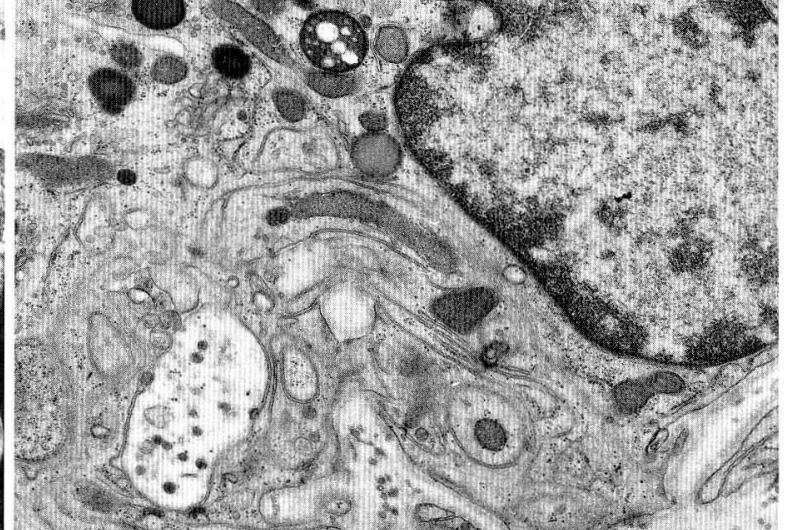

Figs. 6-9. Legends on the opposite page. 
At 1-6 months post-induction, most of the neuronal cell bodies appeared normal. Affected electron dense dendrites were rarely encountered in the interstitial spaces, and those found at this stage were subsequently engulfed by macrophages.

At 9-12 months post-induction, the morphology of the majority of the neuronal cell bodies in the cardiac ganglia appeared normal. No degenerating electron dense dendrites were encountered on the neuronal cell bodies or in the interstitial spaces. However, an occasional macrophage could be encountered in close proximity to the cardiac neurons.

\section{Axon terminals}

At 3-7 days post-induction, numerous degenerating preganglionic axon terminals were found in the interstitial spaces of the cardiac ganglia. Both electron dense and lucent types of degeneration were found. The former type was characterized by the clustering of small agranular synaptic vesicles and glycogen particles in the axon terminals. Moreover, the mitochondria appeared swollen and vacuoles were usually present in the cytoplasm. The electron lucent type of degenerating axon terminal was characterized by an electron lucent cytoplasm containing a few swollen mitochondria and clustered, small agranular synaptic vesicles (Fig. 4). Very often, both types of degenerating axon terminals were closely related to the neuronal cell bodies (Fig. 4).

At 1-6 months post-induction, several freshly degenerating electron dense and lucent axon terminals were found in the interstitial spaces of the cardiac ganglia (Fig. 5). At this stage, several electron dense degenerating axon terminals showed an electron dense cytoplasm containing electron lucent, small agranular synaptic vesicles and pale swollen mitochondria.

At 9-12 months post-induction, degenerating axon terminals were rarely seen. The degenerative debris derived from the affected axon terminals appeared to be engulfed by the infiltrating macrophages in the interstitial spaces.

\section{Myelinated axons}

At 3-7 days post-induction, an occasional degenerating electron dense myelinated axon could be encountered. The degenerating myelinated axon was characterized by the detachment of the myelin membranes (forming small vacuoles) as well as an electron dense or lucent core.

At 1-6 months post-induction, numerous myelinated axons in the cardiac ganglia were affected, with some showing mild alterations while others showed profound degenerative changes (Fig. 6). In most of the degenerating electron dense myelinated axons, there was an increase in electron density of the cytoplasm, an accumulation of neurotubules, neurofilaments and glycogen particles. Some of these axons and their myelin sheaths became highly distorted and disintegrated and were eventually engulfed either by Schwann cells or macrophages (Fig. 7).

At 9-12 months post-induction, degenerating myelinated axons were still recognizable in the interstitial spaces of the cardiac ganglia (Fig. 8). The degenerative debris derived from affected myelinated axons seemed to be engulfed by infiltrating macrophages (Fig. 9). The resulting phagosomes appeared degraded and fragmented (Fig. 9).

\section{Unmyelinated axons}

At 3-7 days post-induction, very few degenerating electron dense or lucent unmyelinated axons were present in the cardiac ganglia. The electron dense type of degenerating unmyelinated axon was characterized by an electron dense cytoplasm containing a few swollen mitochondria, an accumulation of neurofilaments, neurotubules and glycogen particles, and the formation of small vacuoles. The electron lucent type of degenerating unmyelinated axon was characterized by an amorphous cytoplasm containing a few swollen mitochondria, which were usually skewed to the periphery of the axonal profile.

At 1-6 months post-induction, more degenerating unmyelinated axons were seen compared with those

Fig. 6. A myelinated axon in its early stage of degeneration. There are several swollen profiles (possibly mitochondria) in its cytoplasm. The cytoplasm of the Schwann cell is packed with numerous mitochondria (arrows). 3 months post-induction. $\times 9,500$

Fig. 7. A portion of a macrophage found in the neuropil. Note the vacuole $(V)$, electron dense degenerating debris in the cytoplasm and the extending pseudopodia. The engulfed debris appear to be undergoing various stages of degeneration. 3 months post-induction. $\times 9,500$

Fig. 8. A highly disintegrated myelinated axon showing vacuolation, myelin figures and swollen mitochondria in its cytoplasm. Note the continuous band of the disintegrating myelin sheath around the axon. 9 months post-induction. $\times 9,500$

Fig. 9. A portion of a macrophage showing ingested debris and lipid bodies in its cytoplasm. Note the characteristic indented nucleus containing dispersed chromatin materials. 9 months post-induction. $\times 9,500$ 
at 3-7 days. Affected unmyelinated axons showed unidentifiable degenerative debris in their cytoplasm resulting from the fragmentation and dissolution of the cellular organelles.

At 9-12 months post-induction, most of the unmyelinated axons appeared normal. A few degenerating unmyelinated axons were occasionally seen in the interstitial spaces of the cardiac ganglia at this late phase.

\section{DISCUSSION}

The present study has demonstrated neuronal changes in the cardiac ganglia in the rat following the experimental induction of diabetes. During the acute phase (3-7 days), the changes included a darkening of the dendrites and cytoplasm of the cell body, electron dense and lucent types of degenerating axon terminals and degenerating myelinated and unmyelinated axons. In the medium phase (1-6 months), degenerating axon terminals, myelinated as well as unmyelinated axons were consistently observed in the interstitial spaces. During the late phase (9-12 months), only degenerating myelinated and unmyelinated axons were observed. The morphology of the cardiac neurons appeared to be normal. Because of the carefully designed controls, it may be reasonably concluded that the changes observed were due to the experimentally induced diabetes.

The results of our present study have extended the earlier light microscopic observations of TSUJIMURA et al. (1986) on biopsy materials from diabetic patients. These authors described the cellular contraction of the ganglionic neurons, condensation of their cytoplasm and the poor staining of the Nissl substance. They postulated that the changes observed were due to the abnormal metabolism of the autonomic nervous system or diabetic microangiopathy. The neuronal changes described in the dendrites and cell body during the acute phase in the present study are consistent with the light microscopic observations by TsUJimuRA et al. (1986).

TOMLINSON and YUSOF (1983) described a profound neuropathy of the parasympathetic nerves in the atria of diabetic rats. Thus, at the ultrastructural level, they observed an apparent absence of cholinergic terminals (in contrast to numerous adrenergic axon terminals) in the atria of diabetic rats. They concluded that after 7 months, alloxan-induced diabetes caused a parasympathetic denervation of the atria in the rat. Our present observations of degenerating axons and axon terminals in the cardiac ganglia of diabetic rats match those of ToMLINSON and YUSOF (1983), who attributed the changes to metabolic disturbances as a result of diabetes.

The mechanism of degeneration in experimental diabetes is not fully known. The simultaneous changes in neurons and axons observed during the present study are reminiscent of the ultrastructural changes in the cardiac ganglia of the monkey after unilateral and bilateral vagotomy, as described by TAY, WONG and LING (1984) and WONG et al. (1987), respectively. In the latter studies, it was postulated that the vagotomy may have resulted in the diminution or deprivation of a trophic substance that was necessary for the integrity of the cardiac neurons. Along similar lines, it may be speculated that the diabetic condition could have resulted in an autonomic neuropathy in which the vagus nerves underwent degenerative changes as in a surgical vagotomy. Such a possibility appears to exist for the sympathetic system where changes simulating that of sympathectomy have been described in the diabetic condition (Odel, Roth and Keating, 1955). Yet another possibility is the alteration of insulin receptors, whose existence has been demonstrated in the peripheral nervous system (WALDBILLIG and LEROITH, 1987). These may also be present on the vagus nerves and the cardiac neurons. The experimentally induced diabetes could have altered the equilibrium in the interstitial environment and the factors involved in the maintenance of the receptors on the nerves and neurons in the cardiac ganglia, thus resulting in the atrophic and degenerative changes.

Acknowledgements. The authors wish to thank Mr. H. L. CHAN and his staff of the EM Unit for some technical assistance, and Mrs M. SINGH for typing the manuscript.

\section{REFERENCES}

Eluson, J. P. and R. G. HibBs: An ultrastructural study on mammalian cardiac ganglia. J. Mol. Cell. Cardiol. 8: 89-101 (1976).

Kamal, A. A. J., S. S. W. TAY and W. C. Wong: Ultrastructural changes in the cardiac ganglia of streptozotocininduced diabetic rats. Anat. Rec. 220: 50A (1988).

Kobayashi, Y., C. J. S. Hassall and G. Burnstock: Culture of intramural cardiac ganglia of the newborn guinea-pig. I. Neuronal elements. Cell Tiss. Res. 244: 595-604 (1986).

Malor, R., S. TAYlor, C. B. Chesher and C. J. Griffin: The intramural ganglia and chromaffin cells in guinea pig atria: an ultrastructural study. Cardiovas. Res. 8: 731-744 (1974). 
Odel, H. M., G. M. Roth and F. R. Keating: Autonomic neuropathy simulating the effects of sympathectomy as a complication of diabetes mellitus. Diabetes 4: 92-98 (1955).

PAPKa, R. E.: Studies of cardiac ganglia in pre- and postnatal rabbits. Cell Tiss. Res. 175: 17-35 (1976).

Pardini, B. J., K. P. Patel, P. G. Schmid and D. D. LUND: Location, distribution and projections of intracardiac ganglion cells in the rat. J. Auton. Nerv. Syst. 20: 91-101 (1987).

TaY, S. S. W., W. C. Wong and E. A. LING: An ultrastructural study of the neuronal changes in the cardiac ganglia of the monkey (Macaca fascicularis) following unilateral vagotomy. J. Anat. 138: 67-80 (1984).

Tomlinson, D. R. and P. F. Yusof: Autonomic neuropathy in the alloxan-diabetic rat. J. Auton. Pharm. 3: 257-263 (1983).

Tsujimura, T., H. Nunotani, H. Fushimi and T. Inoue: Morphological changes in autonomic ganglion cells of the heart in diabetic patients. Diabetes Res. Clin. Pract. 2: 133-137 (1986).

Viragh, S. and A. Porte: Elements nerveux intracardiaques et innervation du myocarde. Etude au microscope electronique dans le coeur de rat. Z. Zellforsch. 55: 282296 (1961).
W ALDBILLIG, R. J. and D. LeRoITH : Insulin receptors in the peripheral nervous system: a structural and functional analysis. Brain Res. 409: 215-220 (1987).

Wong, W. C., E. A. LING, T. Y. YICK and S. S. W. TAY: Effects of bilateral vagotomy on the ultrastructure of the cardiac ganglia in the monkey (Macaca fascicularis). J. Anat. 150: 75-88 (1987).

YAMAUCHI, A.: Innervation of the vertebrate heart as studied with the electron microscope. Arch. Histol. Jap. 31: 83-117 (1969).

Zypen, H. Van Der, G. Hosselhorst, G. Merz and H. FilLINGER: Histochemische and elektronenmikroskopische Untersuchungen an den intramuralen Ganglien des Herzens bei Mensch und Ratte. Acta Anat. 88: 161-187 (1974).

Dr. S. S. W. TAY

Department of Anatomy Faculty of Medicine National University of Singapore 10, Kent Ridge Crescent Singapore 0511 